Jurnal Lakon, 8 (2) 2019

(78-86)

\title{
ANALISIS SEMIOTIKA PADA CERITA RAKYAT WANDIU-NDIU
}

The Semiotic Analysis of Wandiu-Ndiu Folklore

\section{SALMATIAN SAFIUDDIN}

Program Studi Magister Kajian Sastra dan Budaya

Fakultas Ilmu Budaya Universitas Airlangga

Jl. Dharmawangsa Dalam Selatan, Surabaya 60286

e-mail: salmatian.safiuddin-2018@fib.unair.ac.id

\begin{abstract}
Abstrak: Tradisi lisan adalah sebuah pesan yang disampaikan secara turun- temurun dari generasi tua ke generasi muda. Pesan ini dapat berbentuk cerita rakyat, ucapan, pidato, lagu, dan lain-lain. Objek penelitian ini adalah salah satu cerita rakyat dari Pulau Buton, Sulawesi Tenggara yaitu Wandiu-ndiu. Penelitian ini memiliki dua rumusan masalah. Pertama, bagaimana kode- kode pada cerita rakyat Wandiu-ndiu. Kedua, bagaimana amanat dan fungsi sosial pada cerita rakyat Wandiundiu. Adapun tujuan penelitian untuk mendeskripsikan kode, amanat dan fungsi sosial yang ditemukan dalam cerita rakyat Wandiu-ndiu. Metode yang digunakan adalah kajian pustaka dengan menggunakan teori Semiotika Roland Barthes. Hasil penelitian ini menunjukkan bahwa terdapat lima kode, yaitu 1) kode hermeneutik, 2) kode proairetik/aksi, 3) kode semik/konotatif, 4) kode simbol, dan 5) kode budaya. Amanat yang terdapat dalam cerita rakyat Wandiudiu terdiri dari amanat tersirat dan amanat tersurat. Adapun fungsi sosial dalam cerita rakyat ini, yakni 1) fungsi kebudayaan, 2) fungsi pendidikan, dan 3) fungsi kemasyarakatan. Penelitian ini merupakan upaya pelestarian sastra lisan khususnya cerita rakyat sekaligus membantu pemerintah untuk melestarikan tradisi lisan dan dearah.
\end{abstract}

Kata-kata Kunci: Amanat, Cerita Rakyat, Fungsi Sosial, Kode, Wandiu-Ndiu

\begin{abstract}
Oral tradition is a message conveyed from one generation to the younger generation. The oral tradition like folklore, speeches, songs, etc. The object studied in this article is one of the folklore from Buton Island, Southeast Sulawesi, namely Wandiu-ndiu. The research question is, the first how the codes on the Wandiu-ndiu folklore. Second, what are the mandate and social function of the Wandiu-ndiu folklore. The purpose of the research is to describe the codes, mandates, and social functions found in the folklore of Wandiu-ndiu. The method used is a literature study using Roland Barthes's Semiotic theory. The results of this study indicate that there are five codes namely 1) hermeneutic code, 2) proairetic / action code, 3) semic/ connotative code, 4) symbol code, and 5) cultural code. The message contained in the folklore of Wandiudiu consists of an implied mandate and written message. The social functions in this folklore are 1) the function of culture, 2) the function of education, and 3) the function of society. This research is an effort to preserve oral literature, especially folklore, while at the same time helping the government to preserve oral and regional traditions.
\end{abstract}

Keywords: Code, Folklore, Mandate, Social Function, Wandiu-Ndiu

PENDAHULUAN

Indonesia adalah negara yang kaya akan ragam bahasa dan budaya. Setiap

Jurnal Lakon: Kajian Sastra dan Budaya

e-ISSN: 2527-4899; p-ISSN 2252-8954 
daerah memiliki khasanah kearifan lokalnya masing-masing. Oleh karena itu, Indonesia dikenal dengan semboyannya bhineka tunggal Ika yang berarti walaupun berbeda- beda tetapi tetap satu Indonesia. Indonesia dikelilingi oleh sebagian besar wilayah lautan dan terdiri dari macammacam pulau. Salah satu pulau di Indonesia yang memiliki khasanah kearifan lokalnya adalah Pulau Buton. Dimasa lampau Pulau Buton ini terkenal dengan nama Kerajaan Buton atau Kesultanan Buton. Di sinilah berdiri megah Benteng Keraton Buton yang pada September 2006 mendapatkan penghargaan dari Museum Rekor Indonesia (MURI) dan Guiness Book Record sebagai benteng terluas di dunia dengan luas sekitar 23, 375 Hektar. Awal mulanya, benteng ini didirikan oleh Sultan Buton III, yaitu La Sangaji pada abad ke- 16. Tak seperti sekarang, dahulu benteng hanya dibentuk dari tumpukan batu yang disusun mengelilingi komplek Istana. Dengan tujuan sebagai pagar pembatas antara komplek istana dengan perkampungan masyarakat dan sebagai benteng pertahanan (Ratnasari, 2018). Saat memasuki kawasan benteng Keraton Buton, Kota Bau-Bau Sulawesi Tenggara dapat dijumpai berbagai peninggalan bersejarah dari masa lampau. Salah satu khasanah budaya yang berkembang dan hidup dalam sendi kehidupan masyarakat Buton sejak jaman dahulu adalah sastra lisan atau yang lebih dikenal dengan istilah cerita rakyat.

\section{Dalam Kamus Besar Bahasa} Indonesia, sastra lisan berarti hasil kebudayaan lisan dalam masyarakat tradisional yang isinya dapat disejajarkan dengan sastra tulis dalam masyarakat modern. Sastra lisan juga berarti sastra yang diwariskan secara lisan, seperti pantun, nyanyian rakyat, dan cerita rakyat. Sastra lisan adalah sinonim dari folklor lisan, karena sastra lisan merupakan bagian kebudayaan yang tersebar dan diwariskan turun temurun baik yang disertai dengan gerak isyarat atau alat pembantu pengingat (Danandjaja, 1994: 54). Cerita Wandiu-ndiu adalah cerita rakyat yang lahir di Kepulauan Buton dan merupakan salah satu sastra lisan yang menjadi kekayaan budaya masyarakat Buton. Wandiu-ndiu berarti Ikan Duyung dalam bahasa Indonesia. Cerita ini mengandung nilai-nilai hidup masyarakat Buton sekaligus merefleksikan kondisi sosial budaya masyarakat pesisir Pulau Buton. Maka, menurut peneliti, penting untuk melakukan penelitian terkait tanda- tanda atau kodekode yang tersembunyi dari cerita rakyat pada wilayah Timur Indonesia ini dalam rangka turut membantu pemerintah menggali kekayaan lokal daerah dan menjaga pelestarian tradisi lisan untuk tetap hidup dan berkembang terutama di zaman modern yang sudah memasuki era globalisasi dimana para generasi muda, berkurang kesadarannya untuk memaknai cerita- cerita yang syarat makna dari para terdahulunya.

Penelitian terdahulu telah mengangkat tema tentang gaya bahasa pada sastra lisan Buton atau Wolio di Sulawesi Tenggara. Penelitian yang telah menghasilkan gambaran tentang penggunaan bahasa-bahasa yang digunakan pada tradisi lisan buton seperti hiperbola, metafora, paralelisme, repetisi, dan sebagainya (Nadifah, 2017). Selain itu, sebagian besar studi yang telah dilakukan masih berkisar pada konteks situasi, cara berpikir dan ideologi masyarakat Wolio (Gusnawaty, 2017). Kemudian pada literatur lain, banyak berfokus pada tradisi lisan Wolio lainnya seperti pada pesan kemanusiaan pada puisi Bula Malino karya Kaimuddin Idrus Muhammadalbuthuni 
Ibnu Badaruddin (Sahlan, 2016). Pengetahuan tentang kode-kode yang tersembunyi khususnya pada cerita rakyat di Sulawesi Tenggara sebagian besar hilang dari penelitian sebelumnya. Kenyataannya, masih sedikit literatur yang membahas cerita rakyat Wandiu-Ndiu sehingga ditemukan bahwa cerita rakyat ini kurang dieksplorasi. Dengan demikian, mengetahui lebih dalam terkait kode-kode tersembunyi, amanat dan fungsi sosial dari cerita rakyat ini menjadi penting untuk diketahui. Terutama pada wilayah Sulawesi Tenggara yang merupakan wilayah kepulauan Indonesia.

\section{METODE}

Penelitian ini adalah penelitian kualitatif. Penelitian kualitatif memiliki karakteristik, yaitu: 1) mempunyai latar yang alami sebagai sumber data langsung, 2) bersifat deskriptif, 3) lebih menekankan pada proses daripada hasil, 4) cenderung menganalisis data secara induktif, dan 5) makna merupakan hal yang esensial (Jufri, 2007: 12). Selain itu, metode penelitian kualitatif di artikan sebagai prosedur penelitian yang menghasilkan data deskriptif berupa kata-kata tertulis atau lisan dari orang-orang dan perilaku yang dapat diamati (Bogdan \& Taylor dalam Moleong, 2005:4). Peneliti melakukan langkah awal dengan menganalisis teks cerita rakyat Wandiu-ndiu. Kemudian melakukan rekonstruksi sesuai pendekatan Semiotika Roland Barthes dimana menurut Barthes, suatu karya sastra atau teks merupakan sebentuk konstruksi belaka. Bila hendak menemukan maknanya, maka yang dilakukan adalah rekonstruksi dari bahan-bahan yang tersedia, yang tak lain adalah teks itu sendiri. Sebagai sebuah proyek rekonstruksi, maka pertama-tama teks tersebut dipenggap-penggal terlebih dahulu menjadi beberapa leksia atau satuan bacaan tertentu. Dengan kata lain leksia adalah unit-unit bacaan dimana peneliti melakukan pemenggalan kata mengacu pada kriteria sebagai berikut; 1) kriteria pemusatan, yaitu pemenggalan teks dengan berfokus pada satu titik perhatian seperti berpusat pada peristiwa yang sama; 2) kriteria koherensi, yaitu pemenggalan teks berdasarkan pengurungan kurung waktu dan ruang yang koheren, seperti keadaan atau peristiwa yang ada dalam ruang dan waktu yang sama; 3) kriteria batasan formal, yaitu pemenggalan teks dengan memberikan penanda-penanda formal yang memberi batas antar bagian teks seperti ruang kosong atau penomoran yang menandai pergantian paragraf dan tandatanda formal lainnya; 4) Kriteria signifikasi, yaitu pemenggalan teks yang benar-benar signifikan seperti judul atau hal lain yang dipandang signifikan.

Peneliti menggunakan teori Semiotika Roland Barthes. Penggunaan teori ini dalam menganalisa cerita rakyat Wandiu-ndiu dianggap tepat karena pendekatan semiotik Roland Barthes secara khusus tertuju pada sejenis tuturan atau yang lebih dikenal dengan istilah speech yang disebut Mitos. Menurut Barthes (1983), bahasa membutuhkan kondisi tertentu untuk dapat menjadi mitos, yaitu secara semiotik dicirikan oleh hadirnya tataran signifikasi yang disebut sistem semiologi tingkat kedua. Roland Barthes mengembangkan konsep Ferdinand de Saussure mengenai semiotik mencakup paparan sign (tanda) - signified (pertanda) signifier (penanda). Dalam pandangan Saussure melihat, signifier dan signified merupakan kesatuan, tak dapat dipisahkan, seperti dua sisi dari sehelai kertas. Kemudian dikembangkan oleh Roland Barthes ke beberapa aspek yang lebih luas

Jurnal Lakon: Kajian Sastra dan Budaya 
dan kompleks menyangkut budaya. Barthes melihat aspek lain dari penandaan yaitu "mitos" yang menandai suatu masyarakat. "Mitos" menurut Barthes terletak pada tingkat kedua penandaan, jadi setelah terbentuk sistem sign-signifier-signified, tanda tersebut akan menjadi penanda baru yang kemudian memiliki petanda kedua dan membentuk tanda baru. Jadi, ketika suatu tanda yang memiliki makna konotasi kemudian berkembang menjadi makna denotasi, maka makna denotasi tersebut akan menjadi mitos. Sehingga dalam menganalisis kode, amanat dan fungsi sosial dalam teks cerita wandiudiu sangat cocok menggunakan perspektif semiotika Roland Barthes untuk membongkar kodekode yang berada dalam teks cerita rakyat Wandiu-ndiu.

\section{PEMBAHASAN}

Berdasarkan hasil penelitian, maka ditemukan beberapa bentuk kode yang terdapat dalam cerita rakyat Wandiu- ndiu. Cerita rakyat ini juga memiliki makna atau pesan tersurat dan pesan tersirat. Selain itu, hasil dari analisis semiotika ini juga ditemukan beberapa fungsi sosial atas cerita rakyat ini. Berikut uraiannya :

1. Kode- Kode dalam cerita rakyat Wandiundiu

Kajian semiotika berkaitan dengan pengkajian tanda dan segala sesuatu yang berhubungan dengan tanda, seperti sistem tanda dan proses yang berlaku bagi pengguna tanda (Zoest, 1993: 1). Berdasarkan hasil penelitian yang dilakukan oleh peneliti pada teks cerita rakyat Wandiu-ndiu dari Pulau Buton Sulawesi Tenggara menggunakan analisa semiotika Roland Barthes. Pemahaman kode Roland Barthes akan memudahkan pembaca menilai tingkatan konotasi sebuah teks (Paliang, 2003: 169). Hasil penelitian ini menunjukkan bahwa terdapat lima kode pada teks cerita rakyat Wandiu-ndiu, yaitu 1) kode hermeneutik, 2) kode proairetik/aksi, 3) kode semik/konotatif, 4) kode simbol, dan 5) kode budaya.

Berikut hasil analisa untuk tiap kode yang ditemukan pada penelitian ini :

a. Kode hermeneutik

Kode hermeneutika adalah kode yang terdiri dari unit-unit tanda yang berfungsi untuk mengartikulasikan dialektika yang berupa pertanyaanrespon namun jawaban atau kesimpulan dari kata atau kalimat itu ditangguhkan sehingga menimbulkan teka-teki atau menciptakan misteri dalam cerita atau sastra itu. Dalam cerita rakyat Wandiundiu kode yang ditemukan adalah

\section{"Wandiu-ndiu"}

dalam leksia 1 yang berarti putri duyung. Kata 'Wandiu-ndiu' ini dikategorikan ke dalam kode hermeneutik atau kode tekateki karena dalam pembacaannya akan menimbulkan pertanyaan, apakah ikan duyung yang dimaksud benar-benar ikan duyung sesungguhnya atau penjelmaan seseorang yang menjadi ikan duyung.

b. Kode Proairetik (ACT)

Kode proairetik disebut juga kode aksi biasanya menyatakan serangkaian aksi-aksi yang saling berkaitan satu sama lain atau dengan kata lain ada runtutan cerita. Sehingga kode ini disebut juga kode tindakan. Ditemukan beberapa kode proairetik dalam teks cerita rakyat ini di antaranya: 
"Ibunya memberikan ikan Mas tetapi anak itu tidak mau"

dalam leksia 11, kalimat ini masuk kategori kode proairetik atau kode tindakan karena ada tindakan dari sosok Ibu pada cerita ini, yaitu memberikan ikan Mas kepada anaknya untuk dimakan.

"Bukan mereda marahnya malah tambah marah dan tanpa sadar mengambil perkakas tenun untuk memukul istrinya sampai patahpatah perkakas tenun itu dan menyebabkan istri babak belur, dan meneteskan darah dari hidungnya"

dalam leksia 24, juga dikategorikan kode proairetik karena ada runtutan aksi atau rangkaian aksi yang saling berkaitan mulai dari suami marah kemudian mengambil perkakas tenun lalu memukul istrinya hingga istrinya meneteskan darah dari hidung.

c. Kode Semik

Kode semik adalah dunia konotasi dimana sebuah keadaan dibiarkan tidak stabil, biasanya menunjuk karakter/ tempat atau objek tertentu, memanfaatkan petunjuk "kilasan makna". Selain itu, terdapat kesan atau nilai rasa tertentu dalam pemaknaanya. Berikut kode semik yang ditemukan pada cerita rakyat Wandiu-ndiu:

"Dia mengelus-elus kedua anaknya tersebut dan disusuinya La Mbatambata sampai kenyang" (Leksia 28)

"Di cium dan dipeluknya anak anaknya sepuas-puasnya" (Leksia 29)
Pada penggabungan kedua leksia ini, didapatkan kode Semik karena menggambarkan nilai rasa kasih sayang seorang Ibu terhadap anaknya dimana hakikat seorang Ibu untuk menyusui anaknya kemudian memberi kasih sayang dengan cara dicium dan dipeluk. Sehingga, anak merasakan rasa cinta dari sang Ibu.

d. Kode Simbol (SYM)

Seperti namanya kode simbol, kode ini memiliki banyak tempat dimana sebuah leksia dapat saling bertukar tempat. Banyaknya penanda dalam sebuah konteks bacaan mampu membawa pembaca menafsiri sebuah teks dari satu kemungkinan makna ke kemungkinan makna lainnya. Dalam kasus cerita rakyat ini ditemukan kode simbol sebagai berikut:

"Sesampainya di pantai dia membuka jimat yang melilit di pinggangnya dan diletakkannya di atas batu di pinggir pantai" (Leksia 34)

Dalam leksia 34 ini ditemukan kode Simbol yaitu adanya jimat yang sengaja dilepas oleh sang Ibu sebelum menyelam ke pantai. Saat membaca ini dapat diketahui bahwa ada maksud dari sang Ibu meletakkan jimatnya sebagai simbol sesuatu atau mengisyaratkan suatu hal nantinya. Kemudian di kalimat selanjutanya:

"Di atas batu Wa turungkoleo melihat jimat milik ibunya dan menyimpan sebagai tanda mata dari ibunya" (Leksia 43)

Dalam leksia 43 ini, kembali muncul kalimat terkait jimat yang

Jurnal Lakon: Kajian Sastra dan Budaya 
menggambarkan tanda mata dari sang Ibu untuk anak-anak yang ditinggalkannya.

e. Kode Budaya (REF)

Kode budaya mengindikasikan tipe-tipe pengetahuan. Seperti sosiologi, psikologi, dan lain-lain. Kode budaya merujuk pada seperangkat ilmu pengetahuan yang mendukung teks yang dibaca.

Berikut kode budaya pada analisis cerita rakyat Wandiu-ndiu:

"Maka berangkatlah Ibu Wa Turungkoleo meninggalkan anaknya, mulai dari depan pintu dia merobekrobek sarung dan bajunya lalu dijatuhkan sepanjang jalan agar anak-anaknya muda menemukannya bila anak-anaknya mencarinya besok lusa"

Dalam leksia 33 dikategorikan kode budaya karena ada unsur psikologis yang dapat kita lihat dimana seorang Ibu merasa sayang kepada anaknya, walaupun sang Ibu akan pergi jauh tetapi dia tetap memberikan tanda atau petunjuk kepada anaknya agar mereka dapat bertemu lagi.

2. Amanat atau Pesan pada cerita rakyat Wandiu-ndiu

Amanat yang terdapat dalam cerita rakyat Wandiu-ndiu terdiri dari amanat tersirat dan amanat tersurat. Berdasarkan penelitian yang peneliti lakukan setelah menganalisis teks cerita rakyat Wandiundiu, berikut analisis atau pesan yang terdapat dalam cerita ini:
"Berkatalah dia kepada anaknya yang tua 'sayangilah adikmu, jaga dan pelihara dia dengan baik ! berkata pula dia kepada Lambatambata, andai kata engkau Lambatambata tidak ingin makan ikan garam bapakmu tidaklah aku menderita seperti ini."'

Dalam leksia 30 ini ada pesan tersurat yaitu dalam hubungan persaudaraan, seorang kakak harus menjaga dan memelihara adiknya dengan baik dapat dilihat pada ujaran langsung sang Ibu kepada anak tertuanya. Kemudian pada leksia 49:

"Sementara menyusui Lambatambata, dia berkata "andai saja engkau tidak memilih-milih makanan maka kita tidak akan berpisah kasian anakku"

Ini diperkuat dengan munculnya leksia 39:

"baru saja keluar dari pagar dia melihat sobekan kain milik ibunya, maka berkatalah ia kepada adiknya, andai kemarin engkau tidak makan ikan garam bapak maka tidak akan seperti ini."

Pada leksia 39 dan 49 ini ditemukan juga makna tersirat tentang kepatuhan terhadap orang tua. Seorang anak seharusnya mematuhi perintah kedua orang tuanya selama perintah itu memang baik untuk kemaslahatan bersama. Karena akan ada akibat yang terjadi apabila ada aturan yang dilanggar

3. Fungsi Sosial dalam cerita rakyat Wandiu-ndiu

Fungsi sosial berarti cara bertingkah laku dalam kehidupan bermasyarakat atau 
sosial yang bertujuan untuk mencapai kesejahteraan.

Anshari

(2007) mengklasifikasikan fungsi menjadi empat garis besar didalam penelitiannya yaitu fungsi keagamaan, fungsi pendidikan, fungsi kebudayaan, dan fungsi kemasyarakatan. Namun dalam cerita rakyat Wandiu-ndiu hanya ditemukan tiga fungsi. Adapun fungsi sosial dalam cerita rakyat ini yakni 1) fungsi kebudayaan, 2) fungsi pendidikan, dan 3) fungsi kemasyarakatan. Berikut uraiannya :

\section{a. Fungsi Kebudayaan}

Dapat dilihat pada leksia 33

"Maka berangkatlah Ibu Wa Turungkoleo meninggalkan anaknya, mulai dari depan pintu dia merobekrobek sarung dan bajunya lalu dijatuhkan sepanjang jalan agar anak-anaknya muda menemukannya bila anak-anaknya mencarinya besok lusa."

Dimana dalam kebudayaan, kita diajarkan untuk saling mengasihi baik kasih ibu kepada anak maupun sebaliknya saat anak sudah dewasa. Kita dapat melihat dimana seorang Ibu merasa sayang kepada anaknya, walaupun sang Ibu akan pergi jauh, tetapi dia tetap memberikan tanda atau petunjuk kepada anaknya agar mereka dapat bertemu lagi. Karena semua ibu tentu menyayangi anaknya, pergi sejauh apapun di hati dan jiwanya tentu yang utama adalah kebahagiaan anakanaknya.

b. Fungsi Pendidikan

Dalam leksia 30 dapat dilihat
fungsi pendidikan yang tersurat

langsung pada teks cerita rakyat Wandiu-ndiu:

"Berkatalah dia kepada anaknya yang tua 'sayangilah adikmu, jaga dan pelihara dia dengan baik! berkata pula dia kepada Lambatambata, andai kata engkau Lambatambata tidak ingin makan ikan garam bapakmu tidaklah aku menderita seperti ini'."

Yaitu tentang rasa saling menyayangi satu sama lain dalam ikatan tali persaudaraan. Bahwa sebagai kakak harus menjaga dan memilihara adik dan sebagai adik harus patuh kepada yang lebih tua.

\section{c. Fungsi kemasyarakatan}

Fungsi kemasyarakatan dalam cerita rakyat wandiu-ndiu ini dapat ditemukan pada kalimat:

"berselang beberapa saat maka meredalah marahnya dan menyesali perbuatannya kepada istrinya yang telah pingsan, tidak lama kemudian si istri sadar dan memanggil anakanaknya dan berkata saya akan meninggalkan kalian karena bapak kalian lebih menyayangi ikannya di bandingkan kalian anak-anaknya."

Maka dapat ditarik kesimpulan dari kalimat itu bahwa dalam kehidupan bermasyarakat atau sosial kita harus pandai menahan diri dan mengontrol emosi karena bisa jadi apa yang kita lakukan akan kita sesali untuk selamalamanya. Sehingga harus ada kontrol dalam melakukan hubungan antar masyarakat agar hubungan yang sudah 
dibina tidak rusak hanya karena hal kecil.

\section{SIMPULAN}

Berdasarkan hasil penelitian yang dilakukan oleh peneliti pada teks cerita rakyat Wandiu-ndiu dari Pulau Buton Sulawesi Tenggara menggunakan analisa semiotika Roland Barthes, hasil penelitian ini menunjukkan bahwa terdapat lima kode pada teks cerita rakyat Wandiudiu, yaitu 1) kode hermeneutik, 2) kode proairetik/aksi, 3) kode semik/konotatif, 4) kode simbol, dan 5) kode budaya.

Amanat yang terdapat dalam cerita rakyat Wandiudiu terdiri dari amanat tersirat dan amanat tersurat. Pesan tersurat yaitu dalam hubungan persaudaraan, seorang kakak harus menjaga, dan memelihara adiknya dengan baik. Pesan tersirat yaitu tentang kepatuhan terhadap orang tua. Seorang anak seharusnya mematuhi perintah kedua orang tuanya selama perintah itu memang baik untuk kemaslahatan bersama, karena akan ada akibat yang terjadi apabila ada aturan yang dilanggar.

Adapun fungsi sosial dalam cerita rakyat ini, yakni 1) fungsi kebudayaan, 2) fungsi pendidikan, dan 3) fungsi kemasyarakatan. Fungsi kebudayaan, kita diajarkan untuk saling mengasihi baik kasih ibu kepada anak maupun sebaliknya saat anak sudah dewasa. Kita dapat melihat dimana seorang Ibu merasa sayang kepada anaknya, walaupun sang Ibu akan pergi jauh tetapi dia tetap memberikan tanda atau petunjuk kepada anaknya agar mereka dapat bertemu kembali. Karena semua ibu tentu menyayangi anaknya, pergi sejauh apapun di hati dan jiwanya yang utama adalah kebahagiaan anak- anaknya. Fungsi
Pendidikan yaitu tentang rasa saling menyayangi satu sama lain dalam ikatan tali persaudaraan. Bahwa sebagai kakak harus menjaga dan memilihara adik dan sebagai adik harus patuh kepada yang lebih tua. Terakhir, fungsi kemasyarakatan yang mencakup kehidupan bermasyarakat atau sosial. Kita harus pandai menahan diri dan mengontrol emosi, karena bisa jadi apa yang kita lakukan akan kita sesali untuk selama-lamanya. Sehingga, harus ada kontrol dalam melakukan hubungan antar masyarakat agar hubungan yang sudah dibina tidak rusak hanya karena hal kecil.

\section{UCAPAN TERIMA KASIH}

Penulis mengucapkan terima kasih kepada Lembaga Pengelola Dana Pendidikan (LPDP) selaku pemberi beasiswa pendidikan Indonesia kepada penulis yang telah membiayai studi dan penelitian ini hingga terciptanya tulisan ini.

\section{DAFTAR PUSTAKA}

Anshari. (2011). Representasi Nilai Kemanusiaan dalam Sinrilik Sastra Lisan. Makassar: P2i Press

Barthes, Roland. (1983). Elements of Semiology. New York: Hill and Wang.

Danandjaya, James. (1994). Folklor Indonesia, Ilmu Gosip, Dongeng dan Lain-lain. Jakarta : Grafik Press

Gusnawaty, G., Yastiana, Y., \& Yassi, A. H. (2017). Ideational meaning of butonese foklore: A systemic functional linguistics study. Rupkatha Journal on Interdisciplinary Studies in Humanities, IX (1), 327338. doi: https://dx.doi.org/10.21659/rupkat ha.v9n1.33

Jurnal Lakon: Kajian Sastra dan Budaya 
Jufri. (2007). Metode Penelitian Bahasa, Sastra dan Budaya. Makassar Badan Penerbit UNM.

Moleong, Lexy.J. (2005). Metodologi Penelitian Kualitatif Edisi Revisi. Bandung: PT Remaja Rosdakarya.

Nadifa, H. (2017). Gaya Bahasa dalam Sastra Lisan Wolio (Figurative Language in Oral Literary of Wolio). SAWERIGADING, 23(1), 49-59.doi: http://dx.doi.org/10.26499/sawer.v 23i1.189

Paliang, Yasraf Amir. (2003). Hipersemiotika (Tafsir Cultural Studies atas Matinya Makna). Bandung: Jalasutra

Ratnasari, Bella Cyntia. (2018). Belajar Sejarah Kesultanan di Benteng Keraton Buton, Sulawesi Tenggara. Teori Budaya. Kumparan.

Sahlan, A. (2016). Messages For Humanity In "Bula Malino"(Quiet Moon) (A Poem by Kaimuddin Idrus Muhammadalbuthuni Ibnu Badaruddin). IJLECR-International Journal of Language Education and Culture Review, 2(1), 4351. Doi: https://doi.org/10.21009/IJLECR.02 1.05

Zoest, Aart Van. (1993). Semiotika Tentang Tanda, Cara Kerjanya dan Apa yang Kita Lakukan Dengannya. Jakarta:Yayasan Sumber Agung. 